\title{
Aldehyde Dehydrogenase 1 (ALDH1) Promotes the Toxicity of TRAIL in Non- Small Cell Lung Cancer Cells via Post- Transcriptional Regulation of MEK-1 Expression
}

\author{
Shuang Tian ${ }^{\mathrm{a}}$ Da-Hua Liu ${ }^{\mathrm{b}}$ Dan Wang ${ }^{\mathrm{c}}$ Fu Ren ${ }^{\mathrm{b}}$ Pu Xiaa,b \\ aDepartment of Cell Biology, College of Basic Medical Science, Liaoning Medical University, Jinzhou, \\ ${ }^{b}$ Biological Anthropology Institute, Liaoning Medical University, Jinzhou, 'Department of Histology and \\ Embryology, College of Basic Medical Science, Liaoning Medical University, Jinzhou, China
}

\section{Key Words}

$\mathrm{ALDH} 1 \cdot \mathrm{CSC} \cdot \mathrm{TRAIL} \cdot \mathrm{NSCLC} \cdot \mathrm{MEK} / \mathrm{ERK}$ pathway

\begin{abstract}
Background/Aim: Tumor Necrosis Factor-Related Apoptosis Inducing Ligand (TRAIL)-based therapies have been used in many human cancers. However, some tumors are resistant to TRAIL-induced cell death. Aldehyde dehydrogenase 1 (ALDH1) is a functional marker for identification of CSCs. Methods: In this study, we used the colony formation assay, AnnexinV/ $\mathrm{PI}$ double staining and $\mathrm{PI}$ staining to detect proliferation, apoptosis and cell cycle in $\mathrm{ALDH} 1^{+}$ non-small cell lung cancer (NSCLC) cells with TRAIL treatment. In addition, we established xenograft mouse models to confirm the anti-tumor roles of TRAIL in vivo. Finally, gene array and western blot were used to detect the deeper mechanism of the susceptibility of ALDH1 ${ }^{+}$ NSCLC cells to TRAIL. Results: We confirmed that TRAIL could inhibit proliferation, and induce apoptosis and $\mathrm{G}_{1}$ arrest in ALDH1 ${ }^{+}$NSCLC cells. Correspondingly, TRAIL was associated with decreased tumor size and the favorable survival rate of $\mathrm{ALDH} 1^{+}$cells established xenograft mouse models. ALDH1 could increase the death receptors (DR) 4 and DR5 expression in ALDH1 $1^{+}$NSCLC cells via activating MEK/ERK signaling pathway. Conclusion: ALDH1 protein induced MEK-1 mRNA stability and promoted its translation via its 3'UTR.




\section{Cellular Physiology Cell Physiol Biochem 2018;51:217-227 \begin{tabular}{l|l|l} 
and Biochemistry & Dublished online: 16 November 2018 & $\begin{array}{l}\text { (c) } 2018 \text { The Author(s). Published by S. Karger AG, Basel } \\
\text { www.karger.com/cpb }\end{array}$
\end{tabular} \\ Tian et al.: ALDH1 and TRAIL in NSCLC Cells}

\section{Introduction}

Aldehyde dehydrogenase 1 (ALDH1), a cytosolic detoxifying enzyme responsible for the oxidation of intracellular aldehydes, has been widely used for identifying, isolating, and tracking human cancer stem cells (CSCs) [1]. CSCs, constitute a small fraction of the total cancer cell population, are responsible for cancer development, metastasis, recurrence, and drug resistance [2]. ALDH1 positive cancer cells possess cancer stem-cell properties in many solid tumors, such as gastric cancer [3], lung cancer [4], and breast cancer [5]. In our recent study, we found the negative relationship between the Tumor Necrosis Factor-Related Apoptosis Inducing Ligand (TRAIL) levels and the number of circulating ALDH1 ${ }^{+}$cells from the serum of the patients with non-small cell lung cancer (NSCLC). TRAIL, a member of the TNF cytokine superfamily, is a 281 amino acid type II transmembrane protein [6]. Activated TRAIL could promote apoptosis in a variety of cancer cells by interacting with the death receptors (DR) [7-9].

CSCs are resistant to conventional antitumor treatments, including TRAIL treatment [10]. However, in this study, we found that ALDH1 ${ }^{+}$NSCLC cells are highly susceptible to the toxicity of TRAIL. In the last, we confirmed the mechanisms of this phenomenon. Activation of MEK/ERK signaling pathway was found in ALDH1+ cells. This pathway could increase DR4 and DR5 expression and then provide a target for TRAIL.

\section{Materials and Methods}

\section{Cell culture}

ALDH1 ${ }^{+}$cells were isolated from the serum of the patients with NSCLC and restored in our laboratory. ALDH1 ${ }^{+}$and ALDH1 ${ }^{-}$NSCLC cells were cultured in RPMI-1640 (Hyclone, Logan, UT, USA) supplemented with $10 \% \mathrm{FBS}$ at $37^{\circ} \mathrm{C}$ under an atmosphere of $5 \% \mathrm{CO}_{2}$.

MTT assay

Cell viability was assayed using 3-(4, 5-dimethylthiazolyl)-2, 5-diphenyltetrazoliumbromide (MTT) assays (Sigma-Aldrich, Carlsbad, CA, USA). Briefly, ALDH1 ${ }^{+}$and ALDH1 ${ }^{-}$NSCLC cells were plated in 96-well plates $\left(1 \times 10^{3}\right.$ cells/well). After $24 \mathrm{~h}$, cells were treated with various concentrations of recombinant TRAIL (e.g., 0, 1, 2, 4, 8, $16 \mathrm{ng} / \mathrm{ml}$ for each) (R\&D Systems, Minneapolis, MN, USA). After 48 h, $0.5 \mathrm{mg} / \mathrm{ml}$ MTT was added to each well. Absorbance rates were measured at 550-560 nm using a microplate reader (Bio-Rad, Hercules, CA, USA). IC $_{50}$ values for TRAIL were determined and used in following experiments.

\section{Sphere assay}

As our previous method, cells $\left(5 \times 10^{4}\right.$ cells/well $)$ were plated in 24 -well plates under serum-free, sphere-specific conditions [11]. After culture for 7 days, spheres were fixed in $4 \%$ paraformaldehyde (Sigma Chemicals, St Louis, MO, USA), stained with crystal violet (Beyotime Biotechnology, Shanghai, China), and visible under a light microscope (Olympus CX31, Olympus, Tokyo, Japan).

\section{Flow cytometry analysis}

Cells $\left(1 \times 10^{5}\right)$ were labeled with either PE-conjugated anti-DR4, and anti-DR5 monoclonal antibodies or isotype control (eBioscience, Shanghai, China) for $30 \mathrm{~min}$ at $4^{\circ} \mathrm{C}$ to analyze the expression of death receptors. According to the manufacturer's instructions (KeyGEN, Nanjing, China), cells were stained with Annexin V-FITC and propidium iodide (PI) for apoptosis analysis. For cell cycle analysis, cells were fixed in $70 \%$ cold ethanol at $-20^{\circ} \mathrm{C}$ overnight and next day stained with $1 \mathrm{mg} / \mathrm{ml}$ PI (KeyGEN) for $2 \mathrm{~h}$ at $37^{\circ} \mathrm{C}$ in darkness. DR expression, cell cycle and apoptosis were determined by a FACSCalibur flow cytometer (Becton Dickinson Medical Devices, Shanghai, China). 


\section{Cellular Physiology Cell Physiol Biochem 2018;51:217-227

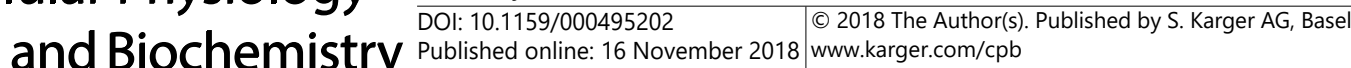 \\ Tian et al.: ALDH1 and TRAIL in NSCLC Cells}

Western blot

Cellular proteins were probed using the following antibodies: anti-ALDH1, anti-DR4, anti-DR5, anti-ERK, anti-phospho-ERK, antiMEK, anti-phospho-MEK, and anti- $\beta$-actin antibodies (Santa Cruz Biotechnology, Santa Cruz, CA, USA). The reaction was followed by probing with peroxidase-coupled secondary antibodies at dilutions ranging from 1:500 to $1: 1000$ (Beyotime Biotechnology), and binding results were visualized via enhanced chemiluminescence (Beyotime Biotechnology).

\section{MEK SIRNA}

To further verify the role of the MEK/ERK signaling pathway, MEK siRNA was applied to cells and reproduced the experiments described above. MEK siRNA was purchased from Cell Signaling Technology (Beverly, MA, USA). Transfection of siRNA was carried using Lipofectamine 2000 (Invitrogen, Carlsbad, CA, USA) in accordance with the manufacturer's protocol.

\section{Xenograft mouse models}

The protocol was approved by the Animal Care and Use Committee of Liaoning Medical University. The NOD SCID mice (male, aged 4-6 weeks) were purchased from the Institute of Animal Center of Chinese Academy of Sciences (Shanghai, China). Tumor xenografts were established by subcutaneous inoculation of $5 \times 10^{6} \mathrm{ALDH}^{+}, \mathrm{ALDH}^{-}$or ALDH1 ${ }^{+}+$si-MEK NSCLC cells into the back of mice. When tumors reached 3-5 $\mathrm{mm}$ in diameter, the mice were then intratumorly injected with $200 \mu \mathrm{l}$ of rTRAIL ( $8 \mathrm{ng} / \mathrm{ml}$; R\&D Systems) every three days. The survival time of mice in each group were observed during the whole process. All animals were sacrificed five weeks post-treatment and tumors were dissected for pathological examination.

\section{cDNA microarray analysis}

Total RNA was extracted from mouse tumor tissues using Trizol reagent (Invitrogen) according to the manufacturer's instructions. Total RNA was labeled with Cy3- and Cy5-conjugated dCTP. The Cy3- or Cy5labeled cDNA was mixed and then placed on an Agilent mouse whole genome microarray and placed in the Agilent microarray hybridization chamber. The fluorescent image of the hybridized microarray was scanned using an Agilent microarray scanner and analyzed using Agilent Feature Extraction software (Agilent Technologies, Beijing, China). Based on the RMA algorithm, the likelihood that the number of focus genes (i.e., differentially expressed genes) within the network was analyzed by the Ingenuity pathway analysis (IPA; Ingenuity ${ }^{\circledR}$ Systems, www.ingenuity.com).

\section{Real-time PCR}

Real-time PCR was performed on an ABI 7500 Real-time PCR System (Applied Biosystems, Foster, CA, USA) using SYBR Green Supermix reagents (TaKaRa, Dalian, China) according to the Manufacturer's instruction. Real-time PCR was carried out as follows: 1 cycle of $95^{\circ} \mathrm{C}$ for $5 \mathrm{~min}$, followed by 40 cycles of $95^{\circ} \mathrm{C}$ for $15 \mathrm{~s}$ and $60^{\circ} \mathrm{C}$ for $35 \mathrm{~s}$. Relative quantitation was calculated by $\triangle \triangle \mathrm{Ct}$ method. Primers used in this study were summarized in Table 1.

\section{Bioinformatic analysis}

To predict the interaction of ALDH1 protein and MEK-1 mRNA 3'UTR, we employed the Nucleic acidProtein Dock (NPDock, http://genesilico.pl/NPDock) [12]. The three-dimensional structure of ALDH1 protein and MEK-1 mRNA 3'UTR were predicted by using the Phyre server (http://www.sbg.bio.ic.ac.uk/ phyre2) and SimRNAweb server (http://genesilico.pl/SimRNAweb), respectively.
Table 1. Primers for target genes used in quantitative realtime PCR

\begin{tabular}{lcc}
\hline mRNA Accession & Gene Symbol & Primers (5' - 3') \\
\hline NM_001290159.1 & ALDH1 & F: GAAAGCCATCCACACAGGACA \\
NM_001043456.1 & ERK & F: TGCCAGTTTTGCACATGGAG \\
& & R: TGGACACCCCACCCCATTTT \\
NM_001043457.1 & MEK & F: TTGATGAAGGCGTGGTTCATC \\
& & R: CCAGTGGTGTGTTCAGCTCAGA \\
NM_003844.3 & DR4 & F: ATGAACTCACTGGTTCTTGGC \\
& & R: TTCGCGTCCGGCTTCCTCAAG \\
NM_003842.4 & DR5 & F: GGGAGCCGCTCATGAGGAAGTTGG \\
& & R: GGCAAGTCTCTCTCCCAGCGTCTC \\
NM_131820.1 & E-cadherin & F: AGCCATGTACGTTGCTATCC \\
& & R: CGTAGCACAGCTTCTCCTTAAT \\
NM_031333.1 & N-cadherin & F: GAGATCCTACTGGACGGTTCG \\
& & R: TCTTGGCGAATGATCTTAGGA \\
NM_112957.3 & Oct4 & F: ATTCAGCCAAACGACCATCT \\
& & R: TCTCACTCGGTTCTCGATACTG \\
NM_002467.5 & C-Myc & F: GCTCCACCTCCAGCTTGTAC \\
& & R: CGAGCTGCTGTCGTTGAGAG \\
NM_002046.5 & GAPDH & F: TGTTCCTACCCCCAATGTGT \\
& & R: TGTGAGGGAGATGCTCAGTG \\
\hline
\end{tabular}




\section{Cellular Physiology Cell Physiol Biochem 2018;51:217-227 and Biochemistry \begin{tabular}{l|l} 
DOI: 10.1159/000495202 2018 The Author(s). Published by S. Karger AG, Basel \\
(c)
\end{tabular}

RNA immunoprecipitation (RIP) assay

RIP assay was performed by using the Magna RIP RNA-binding protein immunoprecipitation kit (Millipore, Billerica, MA, USA) according to the manufacturer's instruction. Briefly, cells were lysed in complete RNA lysis buffer $(100 \mu \mathrm{l}$ of RIP lysis buffer, added $0.5 \mu \mathrm{l}$ of protease inhibitor cocktail and $0.25 \mu \mathrm{l}$ of RNase inhibitor). Then $100 \mu$ l of whole cell extract was incubated with RIP buffer containing magnetic beads conjugated with human anti-ALDH1 antibody, or negative control (mouse IgG, Millipore). To digest the protein, samples were incubated with Proteinase K with shaking. Then immunoprecipitated RNA was isolated. Finally, the $M E K-1$ mRNA was detected by RT-PCR.

\section{Dual luciferase gene reporter assays}

The plasmid pGL3-Luc-MEK1-3'UTR was constructed as the method of Wang et al. [13]. Cells were transfected with either 200 ng pGL3-Luc-MEK1-3'UTR or pGL3-Luc using Lipofectamine 2000 (Invitrogen) according to the manufacturer's instructions. $48 \mathrm{~h}$ after transfection, the transfected cells were lysed for assays of promoter activity using the Dual Luciferase Reporter Assay System (Promega, Madison, WI, USA). The levels of luciferase activity were normalized by Renilla-driven luciferase activity in every experiment.

\section{MEK-1 mRNA stability}

To measure the half-life of MEK-1 mRNA, actinomycin D ( $5 \mu \mathrm{g} / \mathrm{ml}$; BioVision Inc., Wuhan, China) used to suppress RNA biosynthesis was added into the cell culture medium. Total RNA was isolated at the indicated time points and subjected to Real-time PCR analysis. MEK-1 mRNA levels were normalized to $18 \mathrm{~S}$ rRNA.

\section{Analysis of newly translated protein}

Cells were incubated with $1 \mathrm{mCi} \mathrm{L-}\left[{ }^{35} \mathrm{~S}\right]$ methionine and L- $\left[{ }^{35} \mathrm{~S}\right]$ cysteine for $20 \mathrm{~min}$ and then were lysed using RIPA buffer [14]. Immunoprecipitations were carried out for $1 \mathrm{~h}$ at $4{ }^{\circ} \mathrm{C}$ using either a polyclonal antibody recognizing MEK-1 (Santa Cruz Biotechnology). Following extensive washes in TNN buffer (50 mM Tris-HCl [pH 7.5], $250 \mathrm{mM} \mathrm{NaCl} 5 \mathrm{mM}$ EDTA, 0.5\% NP-40), the immunoprecipitated material was resolved by $10 \%$ SDS-PAGE, transferred onto PVDF filters. Protein was detected using the ECL Western Blotting Analysis System (KeyGen).

\section{Statistical analyses}

Data were recorded from three independent experiments. Statistical analyses were performed with GraphPad Prism 5 (GraphPad Software, La Jolla, CA, USA). $P<0.05$ was considered statistically significant, and error bars throughout indicate standard error of the mean.

\section{Results}

Effects of recombinant TRAIL on the proliferation, apoptosis, and cell cycle of ALDH1 ${ }^{+}$and ALDH1 cells

We found that the proliferation rate of ALDH1 ${ }^{+}$cells was significantly decreased after treatment with TRAIL by using MTT assay (Fig. $1 \mathrm{~A}, P<0.05$ ). The $\mathrm{IC}_{50}$ value of TRAIL for ALDH $1^{+}$cells was $7.83 \pm 0.16 \mathrm{ng} / \mathrm{ml}$. However, TRAIL showed no significant effects on ALDH1 ${ }^{-}$ cells (Fig. 1A, $P>0.05$ ). In addition to MTT assay, the ALDH1 ${ }^{+}$and ALDH1' cells' ability to induce mammospheres was investigated by using the colony formation assay. ALDH1 ${ }^{+}$cells with TRAIL treatment exhibited a rather weak mammosphere formation capacity (Fig. 1B, $P$ $<0.05$ ). The capacity of ALDH1 ${ }^{-}$cells did not change with TRAIL treatment (Fig. 1B, $P>0.05$ ). Apoptotic ratio of ALDH1 ${ }^{+}$and ALDH1- cells was detected via AnnexinV/PI double staining and flow cytometry. The treatment of ALDH $1^{+}$cells with TRAIL resulted in a higher apoptotic ratio when compared with non-treated ALDH1 ${ }^{+}$ones (Fig. $1 \mathrm{C}, P<0.05$ ). ALDH1 cells treated with TRAIL showed no higher apoptotic ratio than the non-treated ALDH1 ones (Fig. 1C, $P>0.05)$. We observed an increase in $\mathrm{G}_{1}$-phase from $35.5 \%$ in non-treated ALDH1 ${ }^{+}$cells to $64.3 \%$ in TRAIL-treated ALDH1 ${ }^{+}$ones (Fig. 1D). The expression levels of the functional TRAIL receptors were examined using flow cytometry (Fig. 1E). We found that the higher DR4 and DR5 protein levels in ALDH1 ${ }^{+}$cells than that in ALDH1' ones. Both DR4 and DR5 


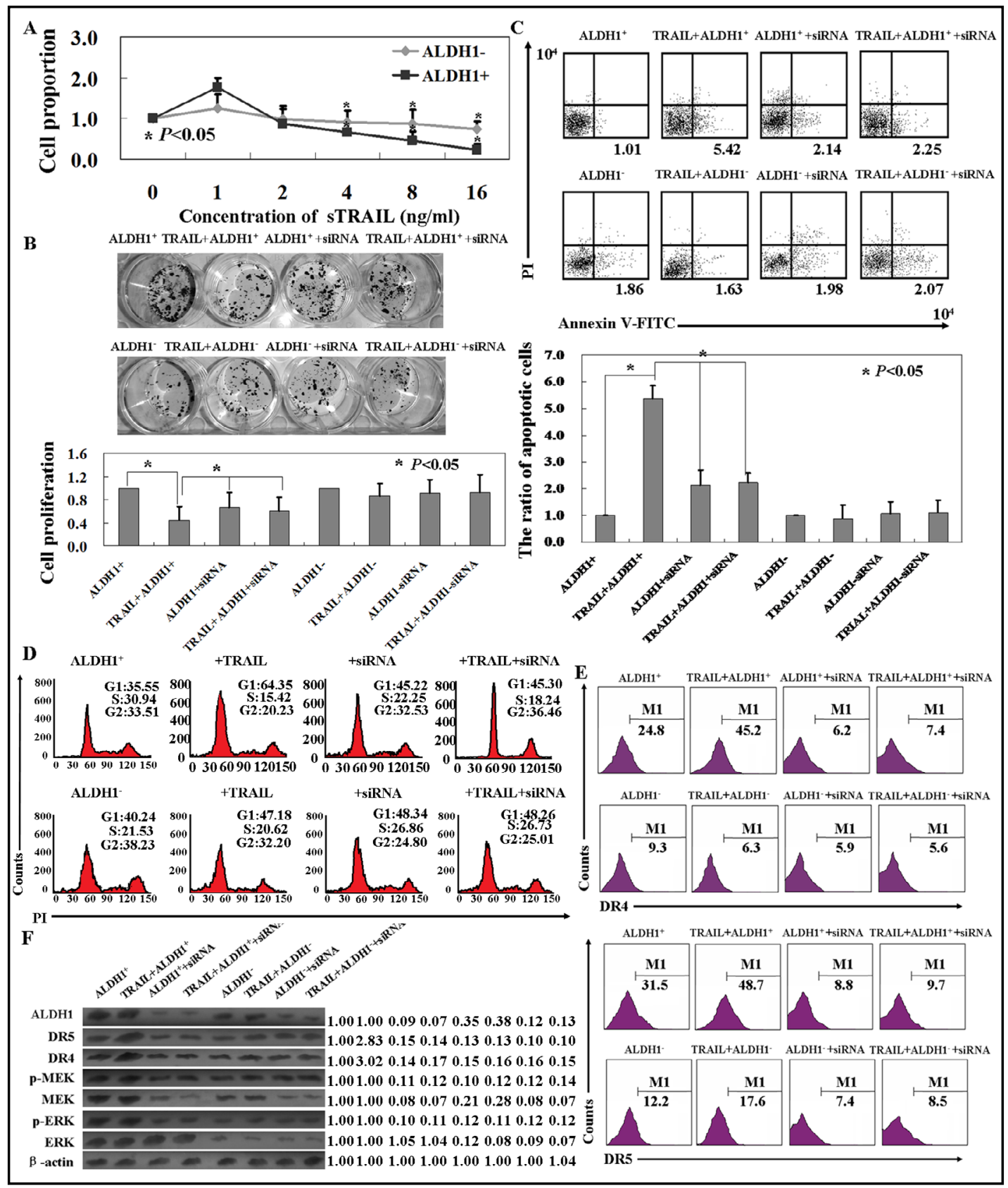

Fig. 1. The roles of TRAIL in ALDH1 ${ }^{+}$and ALDH1 ${ }^{-}$NSCLC cells. The proliferation ratio of cells was detected by using the MTT assay (A) and the colony formation assay (B). (C) The apoptotic cells were determined by using Annexin-V/FITC and PI double-staining. (D) The cell cycle was detected by using PI staining. (E) The cell surface expressions of DR4 and DR5 in cells were detected by flow cytometry. (F) The protein levels were detected by western blot.

levels were increased in TRAIL-treated ALDH1 ${ }^{+}$cells, while no changes in ALDH1 ${ }^{-}$cells with TRAIL treatment. However, when ALDH1 ${ }^{+}$cells were treated with MEK siRNA, anti-tumor roles of TRAIL were offset (Fig. 1). 


\section{Cellular Physiology and Biochemistry Published online: 16 November $2018 \begin{aligned} & \text { DOl: } 2018 \text { The Author(s). Published by S. Karger AG, Base } \\ & \text { www.karger.com/cpb }\end{aligned}$

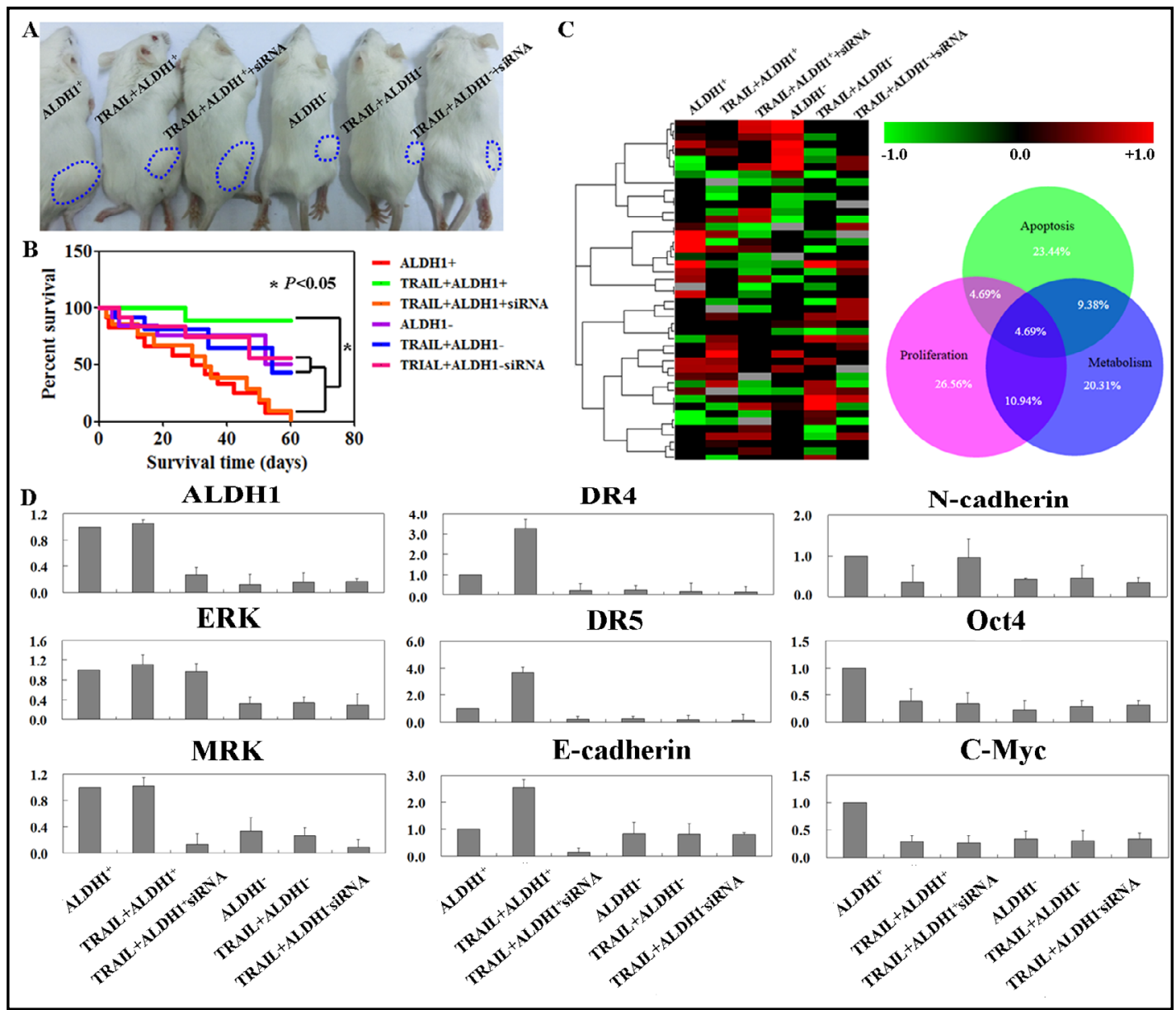

Fig. 2. The role of TRAIL in xenograft mouse models. (A) Macroscopic appearance of subcutaneous tumors in each group described in Materials and Methods. (B) Kaplan-Meier survival curves of the groups described in Materials and Methods. (C) Hierarchical gene cluster analysis. (D) Microarray data validation by Realtime quantitative PCR.

TRAIL reduces tumor growth in $\mathrm{ALDH1} 1^{+}$cells established xenograft mouse models

Based on the above in vitro results, we next determined whether TRAIL displays antitumor properties in established xenograft tumor models. TRAIL reduced tumor size in nude mice carrying ALDH $1^{+}$cell carcinoma (Fig. 2A). In addition, the TRAIL-treated ALDH1 ${ }^{+}$group had a better survival rate compared to that of the non-treated ALDH1 ${ }^{+}$group (Fig. 2B; $P<$ $0.05)$. However, no significant changes were found in the tumor growth and the survival rate of nude mice carrying ALDH1 ${ }^{-}$cells carcinoma after TRAIL treatment (Fig. 2A \& B).

The MEK/ERK signaling pathway plays the central role in TRAIL-induced apoptosis in ALDH1 ${ }^{+}$cells

To determine the mechanisms of TRAIL-induced apoptosis in ALDH1 ${ }^{+}$cells, we measured the changes of the MEK/ERK signaling pathway both in vivo and in vitro. The higher levels of phospho-MEK and phospho-ERK were observed in ALDH1 ${ }^{+}$cells compared with ALDH1 ${ }^{-}$ones, accompanying an increase of both DR4 and DR5 expression (Fig. 1F). To test the hypothesis that ALDH1 could increase DR4 and DR5 expression in ALDH1 ${ }^{+}$cells by activating the MEK/ERK signaling pathway, siRNA targeting MEK was used to treat ALDH1 ${ }^{+}$ ones. siRNA-mediated knockdown of MEK could down-regulate the expression levels of DR4 and DR5 in ALDH1 ${ }^{+}$cells (Fig. 1F). To further dissect the possible molecular mechanisms mediated by ALDH1 expression, microarray was utilized to identify differently expressed 


\section{Cellular Physiology

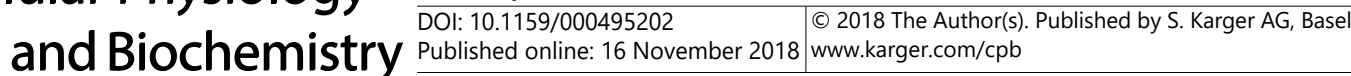

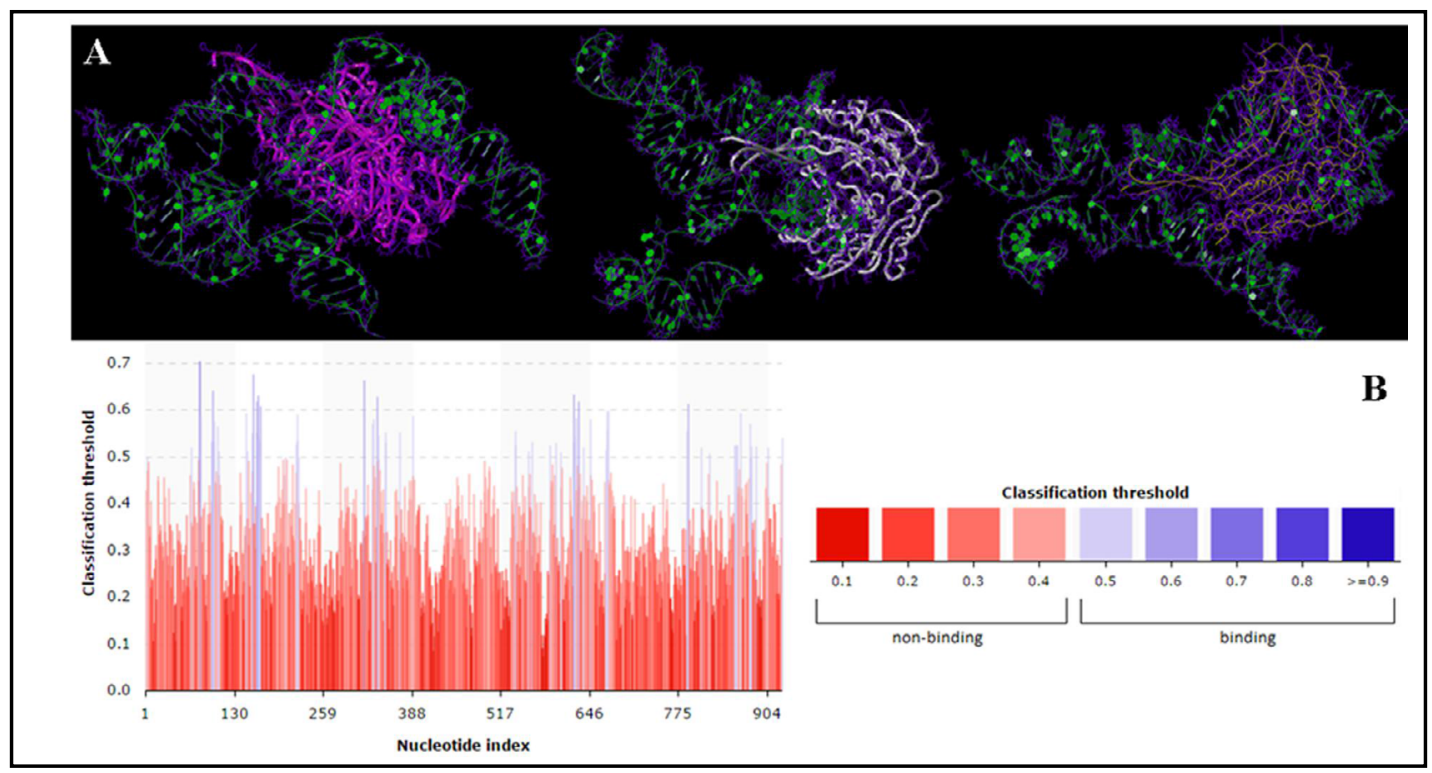

Fig. 3. 3D conformation of MEK-1 3'UTR and ALDH1 protein interaction simulated by NPDock. (A) Structure of complex; (B) Site prediction.

genes in ALDH1 ${ }^{+}$cells and ALDH1 ${ }^{-}$cells. As shown in Fig. 2C, compared to ALDH1 group, 463 up-regulated genes and 522 down-regulated genes were found in ALDH1 ${ }^{+}$group (fold change $>2, \mathrm{P}<0.05$ ). To further confirm the differential genes between the two groups, Realtime PCR was performed. The results showed that ERK, MEK, DR4, DR5, Oct4, and C-myc were highly expressed in ALDH1 ${ }^{+}$group compared with ALDH1- ones (Fig. 2D).

\section{ALDH1 regulates MEK-1 mRNA stability and increases its expression via its 3'UTR}

We further found the deeper mechanism of ALDH1 regulates the expression of MEK1 expression. First of all, we used a web server for protein-nucleic acid docking, NPDock, to simulate the interaction of ALDH1 protein and MEK-1 mRNA 3'UTR. Structure of ALDH1 protein and $M E K-1$ mRNA complex and the interaction sites of complex interface were shown in Fig. 3. To further confirm these findings and to examine whether the translational effect of $M E K-1$ mRNA was exerted through the ALDH1, we used a firefly luciferase reporter gene construct containing the MEK-1-3'UTR and the negative control vector pGL3-Luc (Fig. 4A). As shown in Fig. 4C, ALDH1 induced MEK-1 translation via its 3'UTR as indicated by an increase in MEK-1 luciferase reporter gene activity. By contrast, no changes in the luciferase reporter gene activity were seen in response to ALDH1 when testing a control construct without the 3'UTR. RIP was performed using lysates from ALDH1 ${ }^{+}$cells with ALDH1 antibody, and enrichment of $M E K-1$ mRNA was measured using RT-PCR. The results demonstrated the enrichment of $M E K-1$ mRNA by ALDH1 (Fig. 4B). The MEK-1 mRNA half-life was reduced in ALDH1 ${ }^{-}$cells compared with that measured in ALDH1 ${ }^{+}$ones (Fig. 4D). After the brief incubation period (L-[35S]methionine and L-[35S]cysteine), newly synthesized MEK-1 was markedly increased in ALDH1 ${ }^{+}$cells compared with that measured in ALDH1- ones (Fig. 4E). 


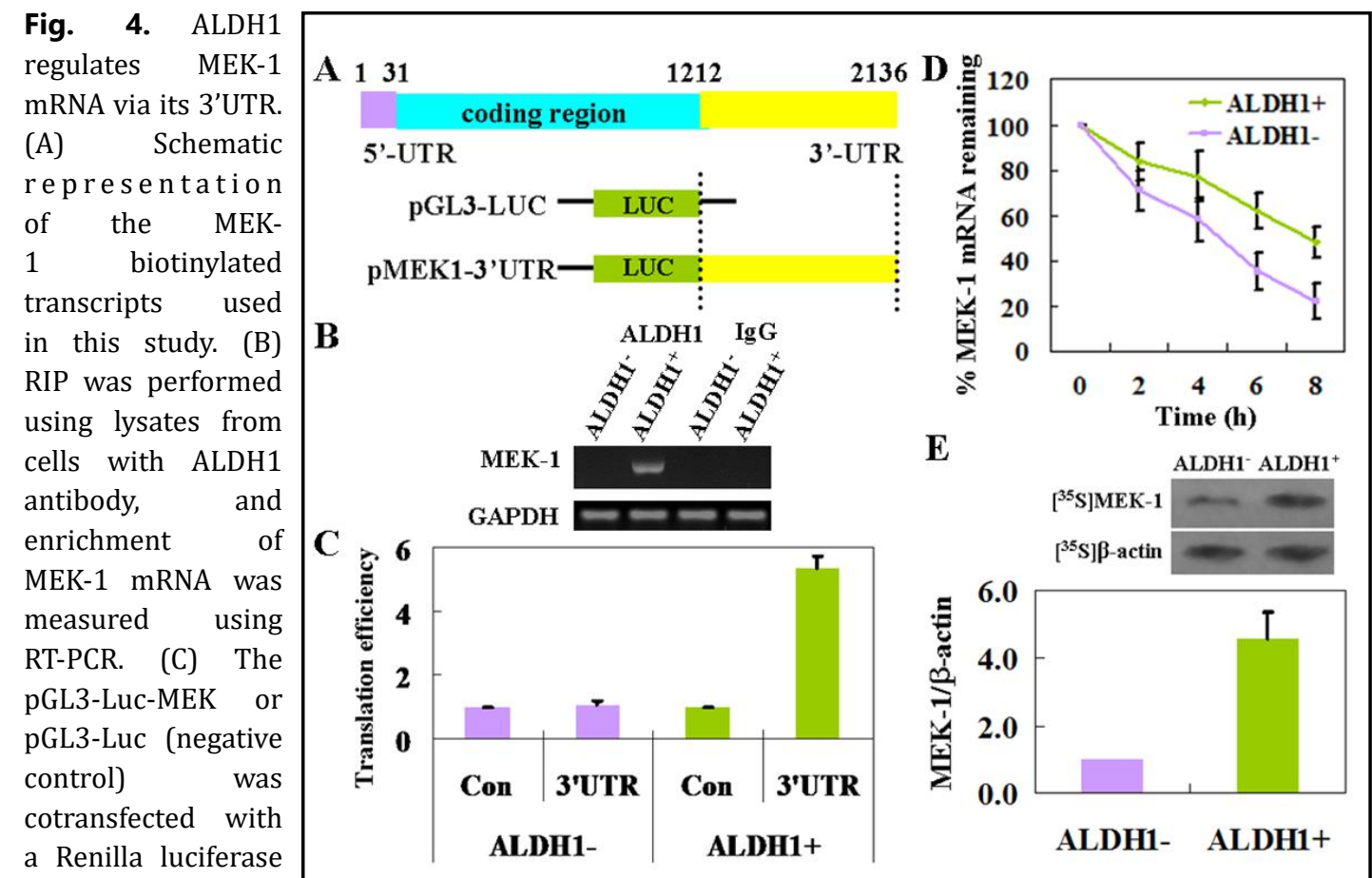

reporter. Firefly and

Renilla luciferase activities were assayed. (D) Half-life of MEK-1 mRNA in cells was measured by Real-time PCR analysis. MEK-1 mRNA levels were normalized to 18S rRNA. (E) Newly synthesized MEK-1 protein in cells were incubated with L-[35S]methionine and L-[35S]cysteine for were detected by using western blot.

\section{Discussion}

TRAIL was initially described as capable of inducing apoptosis in tumor cells without affecting most normal cells [15]. TRAIL-based therapies have been used in many human cancers, including NSCLC [16]. However, many reports showed that some tumors are resistant to TRAIL-induced cell death $[17,18]$. In order to improve the effect of TRAIL on cancer cells, TRAIL has been used in combination with other drugs, such as chaetospirolactone [19], cisplatin [20], gambogic acid [21]. In the study of De Miguel et al [22]., they used Large Unilamellar Vesicles (LUV) to increase the cytotoxicity of TRAIL in human hematological tumor cells. ALDH1 is a functional marker for cancer stem cells [23]. ALDH1 ${ }^{+}$cancer cells have the tumorigenic potential and the capacity for self-renewal and drug resistance [3-5]. Interesting, in this study, we found that ALDH1 ${ }^{+}$NSCLC cells are highly susceptible to the toxicity of TRAIL both in vivo and in vitro. In addition, we found that potential mechanism of TRAIL-induced apoptosis in ALDH1 ${ }^{+}$NSCLC cells by using western blot and microarray. As we known, TRAIL binds with two receptors (DR4 and DR5) to recruit an adaptor protein called FADD, and then to form the death-inducing signaling complex (DISC) followed by activating caspase-8-dependent apoptosis [24]. In this study, we confirmed the higher DR4 and DR5 expression in ALDH1 ${ }^{+}$NSCLC cells. A striking high expression of phosphorylated MEK and ERK was found in ALDH1 ${ }^{+}$NSCLC cells. Previous studies have shown that DR5 and DR4 expression is positively regulated by MEK/ERK signaling [25-27].

MEK-1 activity through its phosphorylation has been confirmed [28-30]. In the present study, we highlight the roles of ALDH1 in the regulation of MEK-1 mRNA stability and translation. We confirmed half-life of $M E K-1$ mRNA and newly synthesized MEK-1 protein was markedly increased in ALDH1+ cells compared with that measured in ALDH1' ones. The result of the luciferase reporter gene showed ALDH1 induced MEK-1 translation via its 3'UTR. All results reported in this study showed that ALDH1 positively regulate expression of the $M E K$ - 
1 gene posttranscriptionally. Altogether, our results suggest that ALDH1 could increase DR4 and DR5 expression in ALDH1 ${ }^{+}$ NSCLC cells via activating MEK/ ERK signaling pathway (Fig. 5A). ALDH1 interacted with the $M E K-1$ mRNA in its 3'UTR and promoted MEK-1 protein expression (Fig. 5B).

\section{Conclusion}

Our study reported the relationship between TRAIL and ALDH1 for the first time. Although ALDH1 and TRAIL are not directly linked, TRAIL can kill ALDH1 positive cancer stem cells through DR4 and DR5. It is precisely because the MEK/ERK signaling in ALDH1 positive cells leads to high DR expression.

\section{Acknowledgements}

This study was supported by National Natural Scientific Foundation of China (81502558) and Biological Anthropology Innovation Team Project of JZMU (JYLJ201702).

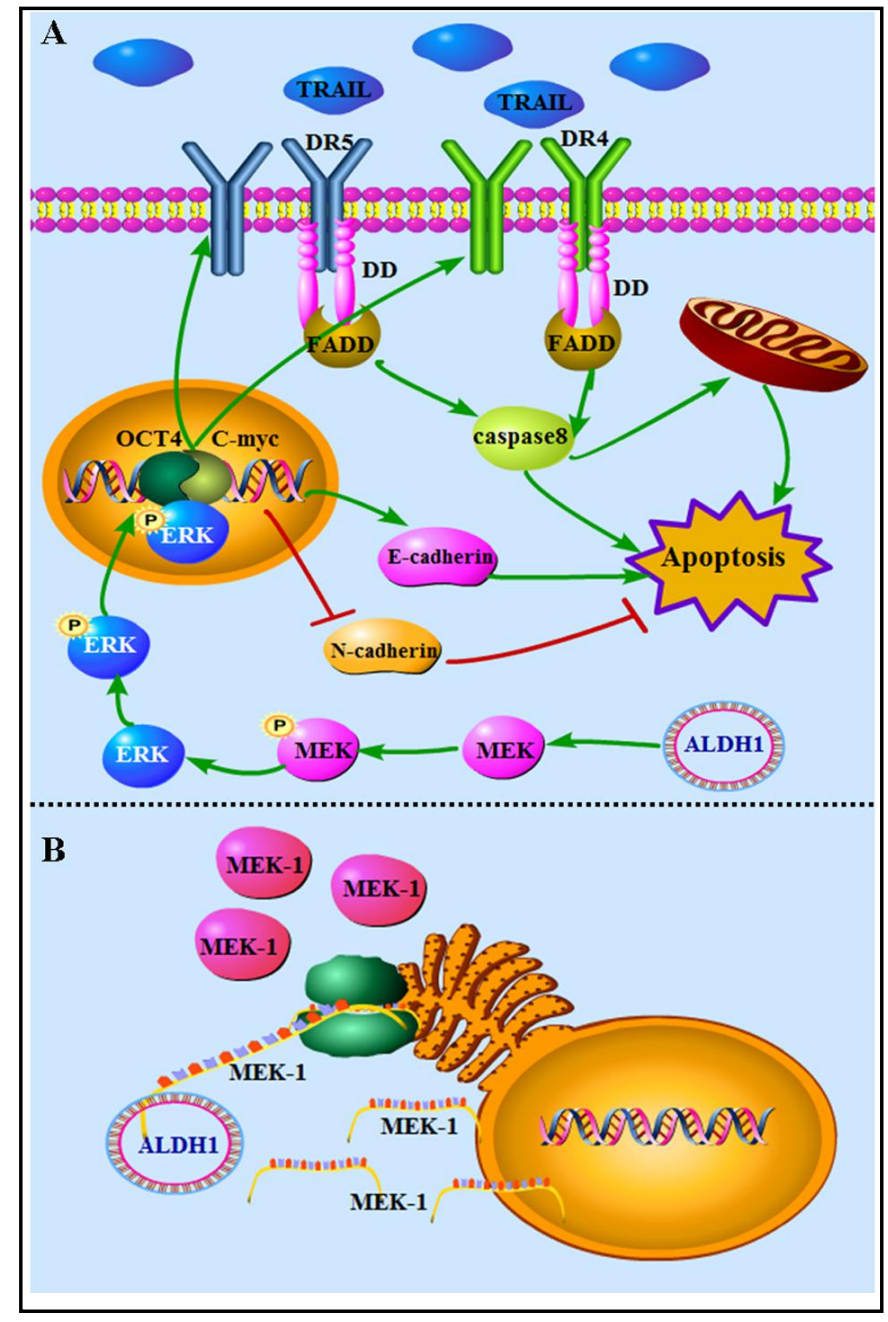

Fig. 5. Schematic model of the mechanism proposed for the increased sensitivity of ALDH1 ${ }^{+}$NSCLC cells to TRAIL-induced apoptosis.

\section{Disclosure Statement}

The authors declare that they have no competing interests.

\section{References}

1 Tomita H, Tanaka K, Tanaka T, Hara A: Aldehyde dehydrogenase 1A1 in stem cells and cancer. Oncotarget 2016;7:11018-11032.

-2 Bakhshinyan D, Adile AA, Qazi MA, Singh M, Kameda-Smith MM, Yelle N, Chokshi C, Venugopal C, Singh SK: Introduction to Cancer Stem Cells: Past, Present, and Future. Methods Mol Biol 2018;1692:1-16.

- 3 Senel F, Kökenek Unal TD, Karaman H, Inanç M, Aytekin A: Prognostic Value of Cancer Stem Cell Markers CD44 and ALDH1/2 in Gastric Cancer Cases. Asian Pac J Cancer Prev 2017;18:2527-2531.

4 Wang J, Wang L, Ho CT, Zhang K, Liu Q Zhao H: Garcinol from Garcinia indica Downregulates Cancer Stemlike Cell Biomarker ALDH1A1 in Nonsmall Cell Lung Cancer A549 Cells through DDIT3 Activation. J Agric Food Chem 2017;65:3675-3683. 


\section{Cellular Physiology Cell Physiol Biochem 2018;51:217-227 and Biochemistry \begin{tabular}{l|l} 
DOI: 10.1159/000495202 2018 The Author(s). Published by S. Karger AG, Basel \\
Published
\end{tabular}

Tian et al.: ALDH1 and TRAIL in NSCLC Cells

5 Nozaki Y, Tamori S, Inada M, Katayama R, Nakane H, Minamishima O, Onodera Y, Abe M, Shiina S, Tamura K, Kodama D, Sato K, Hara Y, Abe R, Takasawa R, Yoshimori A, Shinomiya N, Tanuma SI, Akimoto K: Correlation between c-Met and ALDH1 contributes to the survival and tumor-sphere formation of ALDH1 positive breast cancer stem cells and predicts poor clinical outcome in breast cancer. Genes Cancer 2017;8:628639.

6 Shlyakhtina Y, Pavet V, Gronemeyer H: Dual role of DR5 in death and survival signaling leads to TRAIL resistance in cancer cells. Cell Death Dis 2017;8:e3025.

7 Liang C, Xu Y, Li G, Zhao T, Xia F, Li G, Zhang D, Wu J: Downregulation of DcR3 sensitizes hepatocellular carcinoma cells to TRAIL-induced apoptosis. Onco Targets Ther 2017;10:417-428.

-8 Park SH, Lee DH, Kim JL, Kim BR, Na YJ, Jo MJ, Jeong YA, Lee SY, Lee SI, Lee YY, Oh SC: Metformin enhances TRAIL-induced apoptosis by Mcl-1 degradation via Mule in colorectal cancer cells. Oncotarget 2016;7:59503-59518.

-9 Xu Y, Li J, Li QJ, Feng YL, Pan F: Betulinic acid promotes TRAIL function on liver cancer progression inhibition through p53/Caspase-3 signaling activation. Biomed Pharmacother 2017;88:349-358.

10 Piggott L, Omidvar N, Martí Pérez S, French R, Eberl M, Clarkson RW: Suppression of apoptosis inhibitor c-FLIP selectively eliminates breast cancer stem cell activity in response to the anti-cancer agent, TRAIL. Breast Cancer Res 2011;13:R88.

11 Xia P, Song CL, Liu JF, Wang D, Xu XY: Prognostic value of circulating CD133(+) cells in patients with gastric cancer. Cell Prolif 2015;48:311-317.

12 Tuszynska I, Magnus M, Jonak K, Dawson W, Bujnicki JM: NPDock: a web server for protein-nucleic acid docking. Nucleic Acids Res 2015;43:W425-W430.

13 Wang PY, Rao JN, Zou T, Liu L, Xiao L, Yu TX, Turner DJ, Gorospe M, Wang JY: Post-transcriptional regulation of MEK-1 by polyamines through the RNA-binding protein HuR modulating intestinal epithelial apoptosis. Biochem J 2010;426:293-306.

14 An MX, Li S, Yao HB, Li C, Wang JM, Sun J, Li XY, Meng XN, Wang HQ: BAG3 directly stabilizes Hexokinase 2 mRNA and promotes aerobic glycolysis in pancreatic cancer cells. J Cell Biol 2017;216:4091-4105.

15 Pitti RM, Marsters SA, Ruppert S, Donahue CJ, Moore A, Ashkenazi A: Induction of apoptosis by Apo-2 ligand, a new member of the tumor necrosis factor cytokine family. J Biol Chem 1996;271:12687-12690.

16 Ouyang X, Shi M, Jie F, Bai Y, Shen P, Yu Z, Wang X, Huang C, Tao M, Wang Z, Xie C, Wu Q, Shu Y, Han B, Zhang F, Zhang Y, Hu C, Ma X, Liang Y, Wang A et al.: Phase III study of dulanermin (recombinant human tumor necrosis factor-related apoptosis-inducing ligand/Apo2 ligand) combined with vinorelbine and cisplatin in patients with advanced non-small-cell lung cancer. Invest New Drugs 2018;36:315-322.

17 Micheau O, Shirley S, Dufour F: Death receptors as targets in cancer. Br J Pharmacol 2013;169:1723-1744.

-18 Soria JC, Márk Z, Zatloukal P, Szima B, Albert I, Juhász E, Pujol JL, Kozielski J, Baker N, Smethurst D, Hei YJ, Ashkenazi A, Stern H, Amler L, Pan Y, Blackhall F: Randomized phase II study of dulanermin in combination with paclitaxel, carboplatin, and bevacizumab in advanced non-small-cell lung cancer. J Clin Oncol 2011;29:4442-4451.

19 Hu W, Jia X, Gao Y, Zhang Q: Chaetospirolactone reverses the apoptotic resistance towards TRAIL in pancreatic cancer. Biochem Biophys Res Commun 2018;495:621-628.

-20 Vondálová Blanářová O, Šafaříková B, Herůdková J, Krkoška M, Tománková S, Kahounová Z, Anděra L, Bouchal J, Kharaishvili G, Král M, Sova P, Kozubík A, Hyršlová Vaculová A: Cisplatin or LA-12 enhance killing effects of TRAIL in prostate cancer cells through Bid-dependent stimulation of mitochondrial apoptotic pathway but not caspase-10. PLoS One 2017;12:e0188584.

21 Wang S, Shao M, Zhong Z, Wang A, Cao J, Lu Y, Wang Y, Zhang J: Co-delivery of gambogic acid and TRAIL plasmid by hyaluronic acid grafted PEI-PLGA nanoparticles for the treatment of triple negative breast cancer. Drug Deliv 2017;24:1791-1800.

-22 De Miguel D, Gallego-Lleyda A, Ayuso JM, Erviti-Ardanaz S, Pazo-Cid R, del Agua C, Fernández LJ, Ochoa I, Anel A, Martinez-Lostao L: TRAIL-coated lipid-nanoparticles overcome resistance to soluble recombinant TRAIL in non-small cell lung cancer cells. Nanotechnology 2016;27:185101.

23 Marcato P, Dean CA, Giacomantonio CA, Lee PW: Aldehyde dehydrogenase: its role as a cancer stem cell marker comes down to the specific isoform. Cell Cycle 2011;10:1378-1384.

-24 Thorburn A: Tumor necrosis factor-related apoptosis-inducing ligand (TRAIL) pathway signaling. J Thorac Oncol 2007;2:461-465. 


\section{Cellular Physiology Cell Physiol Biochem 2018;51:217-227 and Biochemistry DOl: 10.1159/000495202 2018 (O 2018 The Author(s). Published by S. Karger AG, Basel

25 Oh YT, Yue P, Zhou W, Balko JM, Black EP, Owonikoko TK, Khuri FR, Sun SY: Oncogenic Ras and B-Raf proteins positively regulate death receptor 5 expression through co-activation of ERK and JNK signaling. J Biol Chem 2012;287:257-267.

-26 Yao W, Oh YT, Deng J, Yue P, Deng L, Huang H, Zhou W, Sun SY: Expression of Death Receptor 4 Is Positively Regulated by MEK/ERK/AP-1 Signaling and Suppressed upon MEK Inhibition. J Biol Chem 2016;291:21694-21702.

-27 Xia P, Wang W, Bai Y: Claudin-7 suppresses the cytotoxicity of TRAIL-expressing mesenchymal stem cells in H460 human non-small cell lung cancer cells. Apoptosis 2014;19:491-505.

-28 Wang Y, Gu J, Lin X, Yan W, Yang W, Wu G: IncRNA BANCR promotes EMT in PTC via the Raf/MEK/ERK signaling pathway. Oncol Lett 2018;15:5865-5870.

29 Cruz E, Kumar S, Yuan L, Arikkath J, Batra SK: Intracellular amyloid beta expression leads to dysregulation of the mitogen-activated protein kinase and bone morphogenetic protein-2 signaling axis. PLoS One 2018;13:e0191696.

30 Awasthi N, Monahan S, Stefaniak A, Schwarz MA, Schwarz RE: Inhibition of the MEK/ERK pathway augments nab-paclitaxel-based chemotherapy effects in preclinical models of pancreatic cancer. Oncotarget 2017;9:5274-5286. 